The Dhaka University Journal of Linguistics: Vol. 2 No.3 February, 2009 Page: 141-160, Published on December 2009 by the Registrar, Dhaka University ISSN-2075-3098

\section{Morphosyntactic Analysis of Mro Language}

\section{Md. Mostafa Rashel ${ }^{1}$}

1. Lecturer, Department of English, Daffodil International University

M.Phil Researcher, Department of Linguistics, University of Dhaka

\begin{abstract}
In this article, I have used many examples to build up a concept about the relationship between Mro morphology and syntax, especially the different case markers to find out the relationship among them. During the research my goal was to provide a description of the constituent order; grammatical categories like tense; comparative marker -la'e (then), -leplepla'e (most); pronominal system (determiners used with first and second person but $3^{\text {rd }}$ person is independent); demonstratives, adverbs, clause combination like conditional markers, reasons, time, motion; structures of question like $y / n$ question, informal, exclamatory; case markers like noun, pronoun (relative), numeral relation to conjunction, suffix, clause/sentence level; grammatical relation (GR) as well as text analysis of Mro language.
\end{abstract}

Key words: Morphosyntax, Language family, Pronominal system, Case marker, Grammatical relation, Mro.

\section{INTRODUCTION}

Mro is a small ethnic minority settled in the hill district of Bandarban, Bangladesh. For a long Mros have been living there with their distinct traditional culture and language. The Dhaka University Journal of Linguistics
According to the report of SIL the population of this language is 30,000 in Bangladesh (2002, SIL), but population census report, 1991 shows as 25339. The total population of all countries is about 81,231. Mros live only in Bandarban of the Chittagong hill tracts. Their key habitats include the remote forest areas of Lama, Ruma, Alikaram and Thanchi near Chimbuk Mountain of the district. Outside of Bangladesh, they also live in the district of Akiab in Myanmar. According to the report of Ethnology there are about 20,000 Mros living in Myanmar (Bradley, 1997; 40). Mros depend mainly on hunting but many of them are also engaged in Jhum cultivation, jautha khamar (collective farming) and gardening. They have no permanent abodes. Buddhist influences are evident in the daily life of Mros. Traditionally Mros are worshipers of nature; however some of them converted to Christianity and a few are Buddhists also. Nowadays quite a few of the people converted to the new religion of Krama founded by a Mro named Manley. Mros introduce themselves as Mro-cha, though they are popularly known as Murongs in CHT. The word mro means man and cha stands for being. On the other hand, the Arakanis and Marma's of Chittagong hill tracts call people of Tripura as Mrong. Again the group of $U z i$ of Tripura living in Bandarban district calls themselves Mrong. Therefore, we should write the name of Mros as Mro instead of Murong.

The Mro are the same as the Murong, who deduce, their origin from tipperah, I have no doubt; though I have doubt about the origin. They were all parts of one and the same division. At the present moment, the Mro are in low condition; fallen from their ancient, high estate. For at one time, a Mro chief was chosen a king of Arakan; and when the Rukheng conquer on invaded the Country, the Country was Mro. However, at present, the Mro are despised. There are 2800 Mros in Arakan. Their present occupancy is somewhat west of their older one. This was on 
the upper Koladyn; when they were expelled by the Kami or Kumi (Latham. 1889)

They have different clans and many sub-clans. According to the source, they have five major clans (Dengua, Premsang, Kongloi, Maizer and Ganaroo Gnar). Others mention ten different Murong clans. They are Yarua, Yaringcha, Tang, Deng, Kough, Tam-tu-chah, Kanbak, Prenju, Naichah and Yomore. The Yarua is the most influential and powerful among the Murong clans. It has four subdivisions (Khatpo, Chimlung, Zongnow, Chawla). These sub-clans are also considered independent clans (Sirajul Islam (ed.). 2003; 423)

\section{Language Family}

Mros are also known as Maru, Marung, Niopring and Murong. 'Murong' means Stranger and the word 'Mro' means Human. Mro's are one of those minor anthropological races of Chittagong hill tracts who have been conserving their own culture, tradition, rituals and customs for a long time. According to the Burma Gazetteer in 1931there were about 2500 Mros in the district of Arakan. Mros do not have any written language. The language they speak has some similarity with Burmese and it seems to belong to the Tibeto-Burman family. In all probability, the Mro language was separated from Tibeto-Burman group at an early period. The Mro vocabulary, syntax and grammar, to some extent, resemble the Kuki-Chin languages of northeastern India and northwestern Myanmar. Mros talk to their neighbors in the local tongue and know Bengali. In this sense, they are bilingual. Mro language has 13\% lexical similarity with Mro Chin (Gordon. 2005[online]). Mros are ethnically related to the Khumi. This language is divided into five linguistically distinct groups: the Anok and Tshungma in the north, Domrong in the lowlands north of the Matamuri, Dopreng and Ruma in the far south and into Arakan
(Brauns and Loffler, 1990[online]). The evolution of the Mro language can be shown with a diagram.

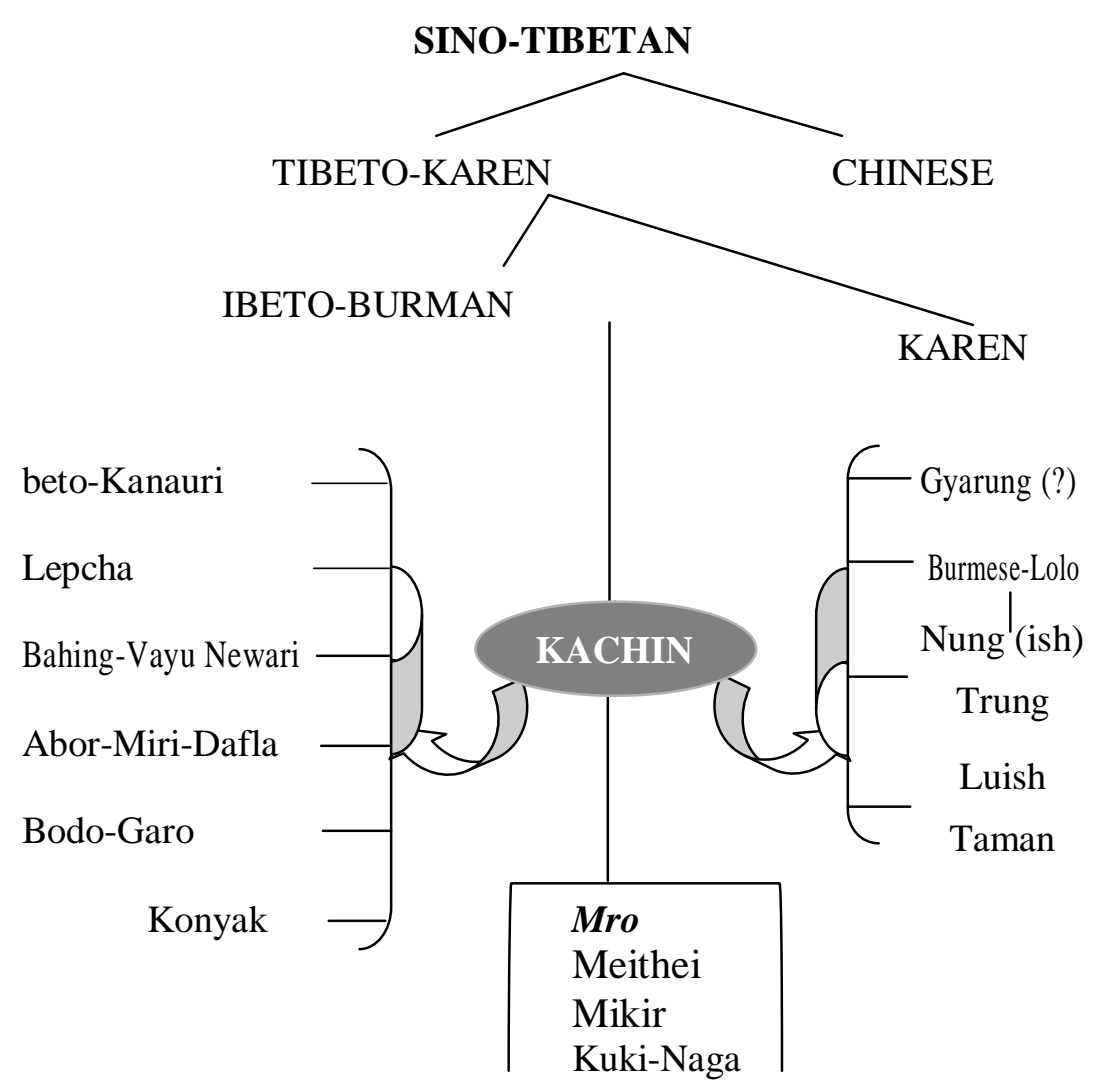

Figure : 1

In the book of Linguistics Survey of India (Grierson. 19011927), Mro language is accredited in the group of Burman and marked as a complex language Mru or Mro is a puzzling language in many respects. In the main it follows the phonetic system of Burmese, and yet it sometimes differs from in material points, presenting, forms which are parallel not only (and most frequently) by those which are meet in kuki-chin, but even by the construction of Bodo and Naga speech. It is 
mainly spoken in North Arakan and A kyab, but a few speakers are also found in the Chittagong Hill Tracts. In spite of different arguments David Bradley's (1997) opinion is much more logical and significant regarding this matter. He said that this language is spoken by about 40,000 people; most of them reside in Arakan state of Burma and some in Bangladesh. Its exact position in Tieto-Burman (TB) is not certain but it shows various layers of contact vocabulary from Kuki-Chin and Burmese. According to Loffler (1966) it is not Kuki-Chin as was suggested some times, but may be remotely related to the Burmese-Lolo group, Shafer $(1967 ; 40)$ also braces this view. The locative division of population by David Bradley (1997) is not appropriate; since majority of the Mros lives in Bangladesh. Being a minor among the minority communities living in Bangladesh with respect to population and language, the majority of the Mros are multilingual. In particular, they know Bengali and Marma besides their mother tongue. That is why lots of Bengali and Marma words are infused into Mro language.

\section{Methodology}

This is a Sociolinguistic research based on field linguistic data. Primary and secondary sources have been used to cover the research. To conduct this research, I focused on qualitative approach. To gather secondary information I have extensively examined the available books, gazettes, records, Internet which are related to Indigenous language issues and other documents. For collecting field level data, I visited Bandarban hill tract, because most of the CHT communities reside there. I had extensive discussion with the key informants of the Mro community. Besides, I have had the opportunity to take faceto-face informal interview. I also used voice recorder while carrying out the audio data collection. A flexible time frame is an important factor for any empirical research. However, this research was done within a three-month time frame that was a

The Dhaka University Journal of Linguistics basic limitation for this study. As a result, this research is not able to highlight all characteristics of Mro language from linguistic views.

\section{Morphosyntactic Analysis \\ 4.1. Constituent Order}

The constituent orders of Mro language are SOV, SVO and OSV. The most important characteristic of this language is the case marker, which is added after the object. So this is not an isolating language like China language. George Grierson (Grierson, 1927) says about the constituent order of Mro language that it is possible to construct all kinds of sentences in this language. Actually, there are no definite rules to constitute a sentence in Mro language. Some examples are given below;
a) I like you -ą enkoj nauki

$$
\mathrm{s} \quad \mathrm{o} \quad \mathrm{V}
$$

b) What is your name? - en min mia $\underline{c o}$

c) I gave Lelung a pig

$$
\text { - }
$$

d) You must go home - en majkom kla $\underline{\mathrm{kim}}$
Paring ate mango
- pariy ca wip ${ }^{h} u m k^{h} っ k$

$\mathrm{s} \quad \mathrm{v} \quad \mathrm{O}$

\subsection{Grammatical Categories}

Tense: The Mro language has no Present Tense marker but it has Present Perfect Tense marker - wi, Past Tense marker $k^{h} \jmath k$ and Future Tense marker -kom. For example-

Vol. 2 No. 3 February, 2009 

a) I go
-ay may (Present tense)
b) I have two cows -ayks cia uj prebok (Present Perfect)
c) Lelung went to market -leluny market koj kəj $\underline{k^{h} o k}$ (Past tense)
d) I went to shop -ay doay koj kəj $k^{h} \jmath k$ (Past tense)
e) I will go

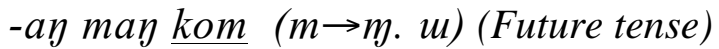

$k \supset j$ used as a locative marker in Past tense but specially in Present tense $k j j$ do not use with 'Own house' (When may is used, then $k o \eta$ will not be used there) otherwise it is used in the middle and after person it is also used as a Nominative manner.

\subsection{Comparative}

A comparative is a construction in which two items are compared according to same quality. Mro language expresses comparison by simply juxtaposing two clauses expressing the degree to which the compared entities exhibit the quality in question. In Mro language we found two compare markers la'e (then) and -leplep la'e (most). Such as;
a) He is taller than me -n'ka an la? e krou
b) She is most beautiful -n'ka leplep la?e klayju

\subsection{Pronominal System}

The Pronominal system of Mro language is different from other CHT languages. In this language Mro people use determiner with first and second person but the third person is independent. This pronominal system is as follows-

$\begin{array}{llll}1^{\text {st }} \text { Person } & \begin{array}{c}\text { Singular } \\ \text { ay }\end{array} & \begin{array}{l}\text { Plural } \\ \text { ayin }\end{array} & \begin{array}{l}\text { Determine } \\ \text { ayciy }\end{array} \\ 2^{\text {nd }} \text { Person } & \text { en } & \text { eniy } & \text { kjjo } \\ 3^{\text {rd }} \text { Person } & n^{\prime} k a & \text { ks:bua } & -\end{array}$

One of the interesting things in Mro language is that the pronominal system is changed according to the age category and plural number. This system is given beneath.

$\begin{array}{llll}\text { Age } & \mathbf{0 1 - 1 5} & \mathbf{1 6 - 3 0} & \text { 31-Up to } \\ \text { Male } & \text { ca?uanema } & \text { klayua } & \text { logtaycama } \\ \text { Female } & \text { mifiuanema } & \text { m'laua } & \text { logtanmifiua }\end{array}$

\subsection{Demonstrative}

Usually every language has a clear class of demonstratives. These are normally free forms and may proceed or follow the nouns they function with. Demonstrative may also be anaphoric on their own, as in what is that?. In which case they may be termed demonstrative pronouns. Demonstratives imply 'pointing to' or 'demonstrating' the object they refer too. e.g., that house (said while pointing to a house), or I will take three of those (said while pointing at some group of objects) (Payne. 1997; 86). Mro language possesses such kind of demonstrative pronouns.

a) This pen is nice - m'ka kolom klayjy

b) That watch is nice - orka nari klayjy

In these examples $m^{\prime} k a$ (this) and orka (that) are used as a demonstrative pronouns.

\subsection{Adverb}

a) He walks slowly - n'ka nauraca may

b) Do the work slowly -namraca cay lup 
here $-c a$ is used as an adverb

c) He speaks loudly -n'ka tunma tæk

d) He ate rice very quickly - n'ka lenma ca hom $k^{h}$ ok

here $-m a$ is used as an adverb and $c a$ is used as a verb.

\subsection{Clause combination}

Adverbial clauses are those that serve an 'adverbial' function. They modify a verb phrase or a whole clause. They are not an argument of the clause. Sometimes adverbial clauses are termed 'adjuncts'. The kinds of information embodied in adverbial clause are the same kinds of information expressed by adverbs, time, place, manner, reasons, conditions etc. Examples will be provided in the following paragraphs. Most of these examples are from Mro language:

\subsubsection{Conditional}

a) If Lelung go Paring will come -leluny kojns pariny may kom

here $-n \supset$ is a conditional marker, wa $\mathrm{kom}$ is used as a future marker.

b) If you want I will help you -en nawns ay $k^{h}$ oy enkom here $-n \supset$ is a conditional marker, $k^{h} o \eta$ is a verb and $\mathrm{kom}$ is used as a future marker.

c) If it does not rain Paring will go to market -uay uay doj no pariy market kom here $-n \supset$ is a conditional marker, $u a \eta$ is a verb, $d \supset j$ is a negative marker, koj is a locative marker and $k o m$ is used as a future marker.

d) If you don't come, I will go. -en way doj caps ay kojkom here -capo is a conditional marker, way is a verb, $d \supset j$ is a negative marker, $k o j$ is a locative marker and $\mathrm{kom}$ is used as a future marker.

\subsubsection{Reason}

a) He did not come because he was ill -n'ka krau n'joyka may ja maydoj here $-n^{\prime} j \jmath \eta k a$ is a conditional reason marker, may is a verb and $d \supset j$ is used as a negative marker.

b) He did not work because he was busy -n'ka jakoj doj lup hu lajks here -lajks is a conditional reason marker, lup is a verb and $d o j$ is used as a negative marker.

c) He ate because he was hungry -n'ka ca tok ${ }^{h}$ k Jak kraj lajks here -lajks is a conditional marker, $c a$ is a verb, $k r a j$ is a suffix, $k^{h} \jmath k$ is used as a past tense marker.

\subsubsection{Time}

Come to our house within five minutes.

-taya minit no ay kimksj way

here -taya is a number marker, way is a verb and $k \supset j$ is used as a locative marker.

\subsubsection{Motion}

I run fast

-ay len jom

here len is a suffix and jom is used as a verb.

\subsection{Structure of question}

4.8.1 Y/N question: In Mro Language, we found $b a$ to make a $\mathrm{Y} / \mathrm{N}$ question. This kind of examples is given below.

a) Will you eat?

-en ca akom ba 
b) Will you go? -en may kom $\underline{b a}$

c) Do you eat? -en ca ba

d) Do you go? -en may $\underline{b a}$

4.8.2 Informational: In Mro Language, we found $t \supset \eta$ to make informational question. This kind of examples is given below-

a) What do you eat? -tonco en ca

b) Where do you go? -en toonkoj cokoj

\subsubsection{Exclamatory}

a) How beautiful the bird is! -ua nomnom klayjy

b) How nice the tree is! - Sin nomnom klayjy

Here nəmnom is used as an exclamation marker and klayj门 is used as an adverb.

\subsection{Case Marker}

Case is very important marker for the languages of the hill tracts as well as in Mro language.

\subsubsection{Noun Marker}

$-k o j-k o j=$ Locative

-ksj (except own home)

$-k \jmath j$ (after person it is used in Nominative manner)

Ex: $\quad$ I gave Lelung the pig that I had

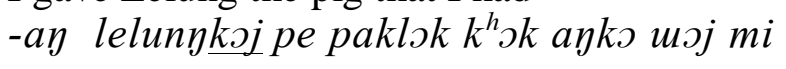

here $-k \supset j$ is a nominative manner because it is used after a person.

$-k J=$ Possessive
Ex : Parin visits his father -pariy n'ka pahon toks

-hon = Associative case

Ex : 1 Paring visited Lelung -pariy lelunyhon $t o k^{h} i k^{h} \partial k$

Ex : 2 Father visited Parin -pa parighon tok ${ }^{h} k^{h}$ ok

Ex : 3 Parin visits his father -pariy n'ka pahon toks

$-m a=$ instrumental commutative

Ex : He speaks loudly

-n'ka tunma tæk

$-k \jmath j$, $-k \jmath b u a=$ Plural

$-k \jmath j o$ is used only two people

-ksbua is used only many people

\subsubsection{Pronoun Marker (relative pronoun)}

Relative pronouns are typically similar to other pronouns in the language; either the question words or the pronouns are used to refer to non-specific, indefinite items. Relative pronouns can be thought of as combining the functions of a plain relativizer and a clause internal pronoun that refers to the relativized Noun phrase. In Mro language we find some relative pronouns such as $-m i,-u j$. Examples are given below.

a) I gave Lelung the pig I had

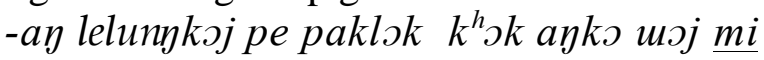
here $k \supset j$ is a nominative manner, $k^{h} \jmath k$ is a past tense marker, $l \supset k$ (one) is a numeral marker and $m i$ is used as a relative pronoun marker.

b) Parin visited the place where Lelung lived -pariy lelunyuj ra koj tok $i$ 
here $k \supset j$ is a locative marker, $u j$ is a suffix, $r a$ (lived) and $t \supset k^{h} i$ (visited) are verb and $m i$ is used as a relative pronoun marker.

c) Lelung who is my friend is a good boy -leluny jyma mi neuma nka ay auja

here $j \eta m a$ is a adjective and $m i$ is used as a relative marker.

\subsubsection{Numeral Relation to conjunction}

\begin{tabular}{|c|c|c|c|}
\hline One [lok] & [rijat] & Thirty & 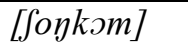 \\
\hline [pre] & [tako] & Thirty one & 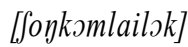 \\
\hline Three [fum] & [muit] & Forty & [likəm] \\
\hline Four [ta:li] & [lailok] & Forty-one & [liksmlailsk] \\
\hline [taya] & [laipre] & Fifty & [yaksm] \\
\hline [tro] & [pirmi] & Fifty-one & [yaksmlaisk] \\
\hline Seven [rinit] & Twenty-one [pirmilailsk] & Hundred & [akom] \\
\hline
\end{tabular}

In Mro language, a conjunction is added after a number and before a noun. Such as;

a) One egg -lok $\underline{c a} d u i$

b) One pig -lok ca pa

c) One man -lok ca muru or muru lok

Here $l o k$ is a numeral marker and $c a$ is used as a conjunction. But when they mean one Mro, then the numeral marker is used after noun and the conjunction will not be used in this case.

d) Two eggs-pre buk dui

e) Two friends -pre buk auja or auja pre

Here pre is a numeral marker and buk is used as a conjunction. But when they mean Two Mro, then the numeral marker is used after noun and the conjunction will not be used in such case.

f) Three eggs -fum buk $d u i$

g) Three horse -fum buk korya

Here $\int u m$ is a numeral marker and buk is used as a conjunction.

The Dhaka University Journal of Linguistics h) Four eggs -ta:li kl'uy dui

Here ta:li is a numeral marker and $k l^{\prime} u \eta$ is used as a conjunction.

\subsubsection{Suffix}

$$
\begin{aligned}
& \text {-hon }=\text { Paring visited Lelung } \\
& \text { - pariy lelunyhon tok } k^{h} k^{h} \supset k \\
& -j o m=\mathrm{I} \text { run fast } \\
& \text {-ay len jom } \\
& -d\lrcorner j=\text { I don't go -ay may } \underline{d o j} \\
& \text { I don't eat -ay ca doj } \\
& -j \mathrm{j} m=\mathrm{I} \text { run fast } \\
& \text {-ay len jom } \\
& -t u k=\text { Lelung sings very well } \\
& \text {-leluny tuk tæk mæy }
\end{aligned}
$$

In Mro language the prefix $a$ is used before adjectives, especially in relative word or to suggest a relationship. It is used, like the corresponding prefix in Burmese in order to form noun from verbs. In Mro language marker is not added to verb. Here verb marker or tense marker is added after object. But any sentence of present tense containing first person singular number can be constructed to express thoughts without adding any marker.

Generally there is no case marker or affix for present tense, although -hom is used occasionally to indicate the present tense, likewise $k^{h} \jmath k$ for past tense and $k o m$ for future tense. In order to make negative sentence negative marker $d o j$ is used after a verb. In Mro language verb case marker never changes with respect to changes in person and number.

Vol. 2 No.3 February, 2009 


\subsubsection{Clause/sentence level}

$-c \supset=$ Informational question

Ex : How many brother and sister do you have? - en nawma en tuama mjnjacs

$-t \supset \eta=$ Informational question

Ex : What do you eat? -toyco en ca

$l a ? e=$ Affirmative statement

Ex : He is taller than me -n'ka ay la? e krou

$-b a=\mathrm{Y} / \mathrm{N}$ question marker

Ex : Will you go? -en may kom $\underline{b a}$

-nэmnэm = Exclamatory

Ex : How beautiful the bird is! -ua nomnom klay i’

$-m a \eta=$ Formal marker

Ex : I go to his house - ay may nôka kim

$-k \jmath k^{\prime} j=$ Informal marker

Ex : I go to his house -aך kok'j n'ka kim

\subsection{Grammatical Relation (GR)}

Grammatical relations (GRs) are often thought of as a relations between arguments and predicates in a level of linguistics structure that is independent of semantic and pragmatic influences. Grammatical expression of semantic roles and pragmatic statuses are understandable in terms of the communicational function of language. However, it is much more difficult to explain GRs in this way.

In order to adequately define grammatical relations, it is convenient to identify three basic semantic-syntactic roles, termed as $\mathrm{S}$ (Single-argument clause), A (Agent) and $\mathrm{P}$ (Patient-multiple arguments clauses). Similar terms are used by Dixson (1972, 1979, 1994) and Silverstein (1976). Presuppose two prototypical clauses in Mro language;

a. Single argument

Paring left

parin mayk $k^{h}$

S V

b. Multi-argument

Paring goes to home

- parin koj kim

$$
\text { A } \mathrm{V} \quad \mathrm{P}
$$

The $\mathrm{S}$ is defined as the only nominal argument of a singleargument clause. This type of clause is referred to as an intransitive clause (SVO>AVP). The A is defined as the most AGENT-like argument of a multi-argument clause. This type of clause is referred to as a transitive clause. If there is no argument that will be a very good AGENT, the $\mathrm{A}$ is the argument that is treated morphsyntactically in the same manner as prototypical AGENT A is treated. The grammatical relation of subject can be defined as $\mathrm{S}$ together with $\mathrm{A}$, while direct 'object' or simply 'object' can be define as P alone. In the following comprehensive discussion, I will try to present some system for grouping S, A, and P through the Morphosyntactic means. Mro language employs to express these grouping.

Mro language treat $\mathrm{S}$ and $\mathrm{A}$ the same and $\mathrm{P}$ is treated differently. The following Mro examples illustrate these facts with pronominal case forms-one form he, is used for third person singular masculine pronouns in both the $S$ and the $A$ roles. A different from him, is used for third person masculine singular pronouns in the $\mathrm{P}$ role: 
a) He left

b) He hit him

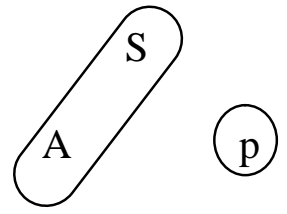

Fig: Nominative/Accusative System

Mro language manifests this system in case marking of free noun phrases. In the following examples the case marker 0 (zero) occurs on noun phrases in both the S (ex. c) and A (d) roles. Another case marker -con occurs on noun phrases in the $P$ role:

c) parin-0 koj "Paring goes"

Paring-NOM goes

$\mathrm{S}$

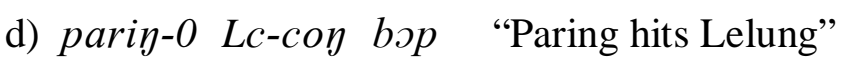

Paring-NOM Lelung- $\underline{\mathrm{ACC}}$ hits
A

\section{$\mathrm{P}$}

This system is referred to as a nominative (NOM)/accusative (ACC) system. The morphological case marks both $\mathrm{S}$ and $\mathrm{A}$ roles, so we can call it nominative case and the case that marks only the $\mathrm{P}$ role is the accusative case. The following examples from Mro language illustrate another system for grouping S, A, and P:

e) pariy tok $k^{h}-k^{h} \jmath k$

"Paring visited"

Paring- ABA visited $\mathrm{S}$

f) pa pariy tok $k^{h}-k^{h} \jmath k \quad$ "Father visited Paring" Father- ERS Paring hon- $\underline{\mathrm{ABA}}$ visited

A $P$

In these examples the case marker - $O$ (zero) occurs on the $\mathrm{S}$ argument of an intransitive clause (e) and the case marker -hon occurs on the $\mathrm{P}$ argument of a transitive clause. The morphological case marks A alone, so it can be called the ergative case. If the morphological case that marks both $\mathrm{S}$ and $\mathrm{P}$ can be termed the absolutive case:

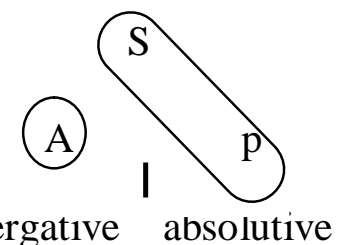

Fig: ergative / absolutive system

In addition to morphological case marking on pronoun or free noun phrases, languages of Mro may manifest ergative/absolutive or nominative/accusative systems in other areas of morphsyntax.

\section{Conclusion}

To collect the data of Mro language, I have conducted an empirical study in the concerned area. They have distinct characteristics in constructing verb and plural numbers. In this regard, Mro language has much more similarity with Kuki-chin language than Burma language. Particularly, it seems to be some oral language that made some significant linguistic influences on Mro language. That is why Mro language seems to hold some contrasting features in tone and verb-related aspects with the languages of Tripura (kokborak) or Manipuri. This Language of western Burma may also be remotely related part of the Burmese-Lolo group and all Burmese-Lolo (BL) languages are verb final with complex tonal and initial consonant system but with little or no morphology.

\section{References}

Bradley, David P. 1997. Tibeto-Burman languages and classification. In Bradley, David (ed.). Canberra: Australian National University. p. 40

Brauns \& Loffler. 1990. Ethnologue: Languages of the World, Sixteenth edition. Dallas, Tex: SIL International. Online version from: http://www.ethnologue.com/.

Dixon, R. M. W. 1994. Ergativity. Cambridge Studies in Linguistics 69. Cambridge University Press. p. 55.59-138 
Grierson, Dr. Sir G. A. 1927. Linguistic Survey of India, Vol. 1 Part 1, Calcutta: Government of India, Central Publication Branch.

Gordon, Raymond G., Jr. (ed.), 2005. Ethnologue: Languages of the World, Fifteenth edition. Dallas, text: SIL International from http://www.ethnologue.com/.

Islam, Sirajul (ed.), 2003. Banglapedia, Dhaka; Asiatic Society of Bangladesh. p. 423

Latham, R. G.1889[1983]. Tribes and Races (Vol-1); Delhi, Culture publishing house. p. 153-154

Payne. E. Thomas. 1997. Describing Morphsyntax. A guide for field linguistics. Cambridge University Press. p. 86, 129, 333

Silverstein, Michael. 1976. Hierarchy of features and ergativity. In Grammatical Categories in Australian Languages, ed. by R. M. W. Dixson. Linguistic Series 22.112-71. Canberra, Australian Institute of Aboriginal Studies.

Shafer, Robert. 1966/1967. Introduction to Sino-Tibetan (Part I: 1966, Part II: 1967). Wiesbaden: Otto Harrassowitz. p. 40

\section{APPENDIX - 1}

\begin{tabular}{|c|c|c|c|c|}
\hline & $\underset{[j o]}{]}$ & $\underset{\text { [ye] }}{L}$ & $\underset{[\mathrm{mi}]}{\mathbf{9}}$ & \\
\hline$\underset{[\text { da }]}{A}$ & $\underset{\text { [a] }}{\mathbf{1}}$ & {$\left[\overline{p^{\mathrm{hi}}}\right]$} & {$\left[\mathrm{k}^{\mathrm{h}} \partial \mathrm{j}\right]$} & [hau] \\
\hline$\bigsqcup_{\text {[dai] }}$ & {$[\mathrm{cu}]$} & [kəu] & [al] & $\underset{[m u m]}{d}$ \\
\hline [nin] & [pa] & [u] & & $\mathbf{9}_{[\mathrm{ro} / \mathrm{ru}]}$ \\
\hline [fi] & $\underset{\left[t^{\mathrm{h}} \partial\right]}{\mathbf{O}}$ & [o] & [ua] & \\
\hline [kㅏ] & [lam] & $\underset{[l a]}{0}$ & $\underset{\text { [hai] }}{\mathbf{y}}$ & \\
\hline [tæk] & & & & \\
\hline
\end{tabular}

Figure-1: Chart of Mro letters (31), in alphabetical order (reading from the left to right)

The Dhaka University Journal of Linguistics
APPENDIX - 2

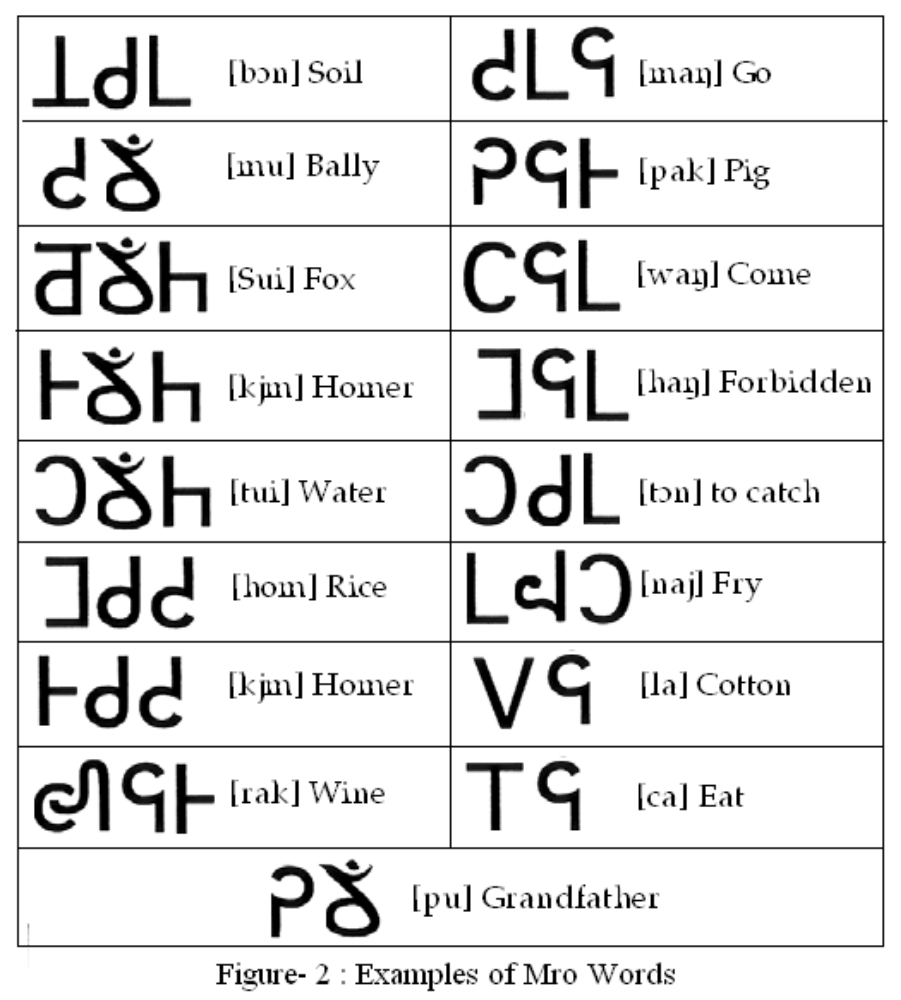

E-mail Contact: md.mostafa_rashel@hotmail.com 